\title{
Spores of Clostridium engineered for clinical efficacy and safety cause regression and cure of tumors in vivo
}

\author{
John T. Heap ${ }^{1,5, *}$, Jan Theys ${ }^{2, *}$, Muhammad Ehsaan ${ }^{1}$, Aleksandra M Kubiak ${ }^{1}$, Ludwig \\ Dubois $^{2}$, Kim Paesmans ${ }^{2}$, Lieve Van Mellaert ${ }^{3}$, Richard Knox ${ }^{4}$, Sarah A. Kuehne ${ }^{1}$, \\ Phillipe Lambin ${ }^{2}$ and Nigel P. Minton ${ }^{1}$ \\ ${ }^{1}$ Clostridia Research Group, Centre for Biomolecular Sciences, School of Life Sciences, The University of Nottingham, \\ University Park, Nottingham, UK. \\ ${ }^{2}$ Maastro Lab, Research Institute GROW, University of Maastricht, MD Maastricht, The Netherlands. \\ ${ }^{3}$ Molecular Bacteriology, Rega Institute for Medical Research, University Leuven, Minderbroedersstraat,Belgium. \\ ${ }^{4}$ Morvus Technology Limited, Ty Myddfai, Llanarthne, Carmarthen, UK. \\ ${ }^{5}$ Present address: Centre for Synthetic Biology and Innovation, Department of Life Sciences, Imperial College London, \\ London, UK. \\ * These authors contributed equally \\ Correspondence to: Nigel P Minton, email: nigel.minton@nottingham.ac.uk
}

Keywords: Clostridia; spores; hypoxia; pro-drug converting enzyme; nitroreductase; CB1954; solid tumor

Received: December 17,2013 Accepted: January 12,2014 Published: January 12, 2014

This is an open-access article distributed under the terms of the Creative Commons Attribution License, which permits unrestricted use, distribution, and reproduction in any medium, provided the original author and source are credited.

\section{ABSTRACT:}

Spores of some species of the strictly anaerobic bacteria Clostridium naturally target and partially lyse the hypoxic cores of tumors, which tend to be refractory to conventional therapies. The anti-tumor effect can be augmented by engineering strains to convert a non-toxic prodrug into a cytotoxic drug specifically at the tumor site by expressing a prodrug-converting enzyme (PCE). Safe doses of the favored prodrug CB1954 lead to peak concentrations of $6.3 \mu \mathrm{M}$ in patient sera, but at these concentration(s) known nitroreductase (NTR) PCEs for this prodrug show low activity. Furthermore, efficacious and safe Clostridium strains that stably express a PCE have not been reported. Here we identify a novel nitroreductase from Neisseria meningitidis, NmeNTR, which is able to activate CB1954 at clinically-achievable serum concentrations. An NmeNTR expression cassette, which does not contain an antibiotic resistance marker, was stably localized to the chromosome of Clostridium sporogenes using a new integration method, and the strain was disabled for safety and containment by making it a uracil auxotroph. The efficacy of Clostridium-Directed Enzyme Prodrug Therapy (CDEPT) using this system was demonstrated in a mouse xenograft model of human colon carcinoma. Substantial tumor suppression was achieved, and several animals were cured. These encouraging data suggest that the novel enzyme and strain engineering approach represent a promising platform for the clinical development of CDEPT.

\section{INTRODUCTION}

Biotechnology potentially offers unconventional routes to new cancer therapies, and research in this area has focused on using viruses as vectors to deliver therapeutic genes to tumors. Unfortunately, issues with the safety of viral vectors have been encountered $[1,2]$ and only recently has a virus system showing good specificity and tumor infiltration been described [3]. Several types of bacteria have also been investigated as delivery vectors, and as therapeutics in their own right $[4,5]$. Spores of some species of Clostridium, which are strictly anaerobic bacteria, naturally target tumors with high specificity following intravenous administration, because the dormant spores can germinate and grow only in the hypoxic/ necrotic cores of solid tumors [6-8] which are difficult 
to target using viral vectors $[9,10]$. The growing bacteria secrete proteases inside the tumor, rapidly digesting the tumor mass. This approach is especially interesting because it directly targets the hypoxic cells in poorly vascular regions which are refractory to conventional treatments. Any Clostridium cells entering normal tissue from a colonized tumor would be poisoned by oxygen and die.

Stringent spacial containment by oxygen is an excellent safety feature, absent from treatments using bacteria that are not strict anaerobes $[11,12]$, but it also allows neoplastic cells at the oxygenated tumor periphery to escape proteolysis [13]. Therefore, we and others have sought to augment the anti-tumor effect of Clostridium strains by genetically modifying them to express therapeutic proteins, mainly enzymes which sensitize the tumor to specific chemotherapeutic agents [14-20]. The prodrug CB1954 (5-(aziridin-1-yl)-2,4-dinitrobenzamide) shown in Figure 1 is an attractive candidate because its clinical safety has been demonstrated [21], and because a 10,000-fold increase in toxicity is achieved upon its activation by a suitable nitroreductase (NTR) enzyme to the 4-hydroxylamine (4HX) derivative 5-(aziridin-1-yl)4-hydroxylamino-2-nitrobenzamide. The 4HX derivative forms a potent DNA cross-linking agent $[22,23]$ which, importantly, has been shown to kill both proliferating and non-proliferating cells [24], both of which are present in hypoxic tumor areas.

Encouraging preclinical efficacy data have been achieved with genetically engineered NTR-expressing Clostridium [19, 20]. However, for this ClostridiumDirected Enzyme-Prodrug Therapy (CDEPT) using CB1954 to be suitable for clinical evaluation, two issues must be addressed. Firstly, the poor kinetics of CB1954 activation by known NTRs must be improved upon. The maximum concentration of CB1954 which can be safely achieved in patient serum is only $6.3 \mu \mathrm{M}$ [21], at which concentration previously-reported enzymes are not saturated. Secondly, a recombinant Clostridium strain must be constructed with properties appropriate for clinical application. The DNA encoding the prodrug-converting enzyme should be stably localized to the chromosome rather than carried by a plasmid, antibiotic-resistance gene(s) used during strain construction must be removed, and preferably the organism should be disabled to prevent its growth in the event of a release into the environment. A strain meeting these criteria has not been described in any report to-date. Here we solve each of these problems and demonstrate the efficacy of CDEPT in a mouse xenograft model of human colon carcinoma, using CB1954 and a recombinant Clostridium strain potentially suitable for clinical trial.

\section{RESULTS}

\section{A novel NTR which efficiently activates CB1954 at clinically-achievable concentrations}

Known enzymes with NTR activity against CB1954 are $\mathrm{NAD}(\mathrm{P}) \mathrm{H}$-dependent quinone reductases belonging to one of two large protein families, Pfam PF00881 'Nitroreductase' and Pfam PF02525 'Flavodoxin_2', such as E. coli NfnB [25] and Bacillus amyloliquefaciens YwrO [26] respectively. We identified homologs of these proteins in the genome sequences of organisms or genomic DNA available in our laboratory (see Supporting Information), and investigated the activity of several of these against CB1954. Each gene encoding a candidate CB1954-activating enzyme was cloned in an E. coli expression vector. Crude cell lysates were used in initial screens for functional expression, and then to test for CB1954 nitroreductase activity using an HPLC assay (see Supporting Information). CB1954 was rapidly consumed by cell lysates containing the $\mathrm{NfnB}$ homolog from Haemophilus somnus 129PT or Neisseria meningitidis MC58. Therefore these two enzymes, which we designate HsoNTR and NmeNTR respectively, were studied in more detail.

NmeNTR and HsoNTR were each affinity-tagged, over-expressed, purified, and the CB1954 nitroreductase activities of the purified proteins characterized using the HPLC assay. The reaction products and kinetic parameters of these enzymes with respect to CB1954 and NADH were determined (Table 1). Both NmeNTR and HsoNTR reduce CB1954 only at the 4-nitro group,

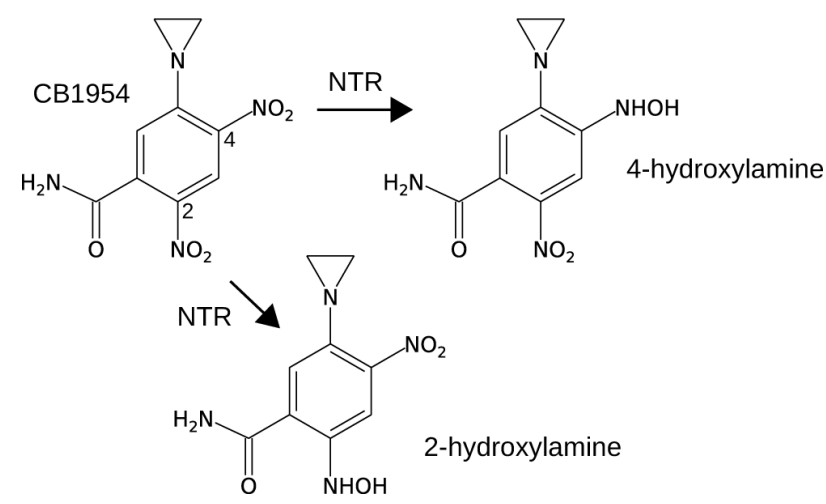

Figure 1: The prodrug CB1954 is a low-toxicity monofunctional DNA-alkylating agent, but can be converted to a much more toxic bifunctional DNAalkylating agent upon 2 x 2 -electron reduction of the 4-nitro or 2-nitro group to the corresponding hydroxylamine. The 4-hydroxylamine is more cytotoxic than the 2-hydroxylamine. Some NAD(P)H-dependent nitroreductase (NTR) enzymes can catalyse this reaction, with varying kinetics and nitro group specificity (see Table 1). 
Table 1: CB1954 nitroreductase properties of selected enzymes.

\begin{tabular}{|c|c|c|c|c|c|c|}
\hline Enzyme & $\mathrm{K}_{\text {cat }}\left(\mathrm{s}^{-1}\right)$ & $\mathrm{K}_{\mathrm{m}}^{\mathrm{CB} 1954}(\mu \mathrm{M})$ & \begin{tabular}{|l}
$\mathrm{K}_{\mathrm{cat}} / \mathrm{K}_{\mathrm{m}}{ }^{\mathrm{CB} 1954}$ \\
$\left(\mathrm{~s}^{-1} \mu \mathrm{M}^{-1}\right)$
\end{tabular} & $\begin{array}{l}\mathrm{K}_{\mathrm{m}}^{\mathrm{NADH}} \\
(\mu \mathrm{M})\end{array}$ & Products & Source / Comment \\
\hline NmeNTR & \begin{tabular}{|l|}
4.04 (NADH) \\
15.23 (NADPH)
\end{tabular} & 2.47 & $\begin{array}{l}1.636 \text { (NADH) } \\
6.166 \text { (NADPH) }\end{array}$ & 188 & $4 \mathrm{HX}$ & $\begin{array}{l}\text { NTR from Neisseria } \\
\text { meningitidis MC58 (this } \\
\text { study). Lowest } \mathrm{K}_{\mathrm{m}}^{\mathrm{CB} 1954} \text { and } \\
\text { highest } \mathrm{K}_{\text {cat }} / \mathrm{K}_{\mathrm{m}}^{\mathrm{CB} 1954} \text { values } \\
\text { of any reported enzyme. }\end{array}$ \\
\hline HsoNTR & \begin{tabular}{|l|}
3.5 (NADH) \\
13.13 (NADPH) \\
\end{tabular} & 22.03 & $\begin{array}{l}0.159 \text { (NADH) } \\
0.596 \text { (NADPH) }\end{array}$ & 644 & $4 \mathrm{HX}$ & $\begin{array}{l}\text { NTR from Haemophilus } \\
\text { somnus 129PT (this study). }\end{array}$ \\
\hline $\mathrm{NfnB}$ & 6 & 862 & 0.007 & 6 & $4 \mathrm{HX}+2 \mathrm{HX}$ & $\begin{array}{l}\text { Widely-studied } E \text {. coli NTR } \\
\text { (Knox et al., 1992). }\end{array}$ \\
\hline $\begin{array}{l}\text { NfnB } \\
\text { N71S/ } \\
\text { F124K }\end{array}$ & 7.5 & 170 & 0.044 & 5 & $4 \mathrm{HX}+2 \mathrm{HX}$ & $\begin{array}{l}\text { Mutant obtained by protein } \\
\text { engineering (Searle et al., } \\
2004 \text { and Race et al., 2007). }\end{array}$ \\
\hline HinNTR & 56.2 & 690 & 0.081 & ND & $4 \mathrm{HX}$ & $\begin{array}{l}\text { NTR from Haemophilus } \\
\text { influenzae (Theys et al., } \\
\text { 2006). Highest } \mathrm{K}_{\text {cat }} \text { value of } \\
\text { any reported enzyme. }\end{array}$ \\
\hline NfsA & $\begin{array}{l}2.60 \text { (NADH) } \\
20.9(\mathrm{NADPH})\end{array}$ & \begin{tabular}{|l}
18 (NADH) \\
140 (NADPH) \\
\end{tabular} & 0.15 & ND & $2 \mathrm{HX}$ & $\begin{array}{l}\text { A second E. coli NTR (Vass } \\
\text { et al., 2009). }\end{array}$ \\
\hline BliNTR & 6.4 & 30 & 0.213 & 820 & $4 \mathrm{HX}$ & $\begin{array}{l}\text { NTR from Bacillus } \\
\text { licheniformis (Emptage } \\
\text { et al., 2009.) }\end{array}$ \\
\hline $\begin{array}{l}\text { FRase I } \\
\text { F124W }\end{array}$ & 26.6 & 259 & 0.103 & ND & $4 \mathrm{HX}$ & $\begin{array}{l}\text { Mutant of FRase I from } \\
\text { Vibrio fischeri obtained by } \\
\text { protein engineering (Swe } \\
\text { et al., 2012). }\end{array}$ \\
\hline
\end{tabular}

The enzymes shown include those with the most favourable values reported for $\mathrm{K}_{\text {cat }}, \mathrm{K}_{\mathrm{m}}{ }^{\mathrm{CB} 1954}$, and $\mathrm{K}_{\text {cat }} / \mathrm{K}_{\mathrm{m}}{ }^{\mathrm{CB} 1954}$.

producing the highly toxic $4 \mathrm{HX}$ derivative. This contrasts with the widely-studied $E$. coli $\mathrm{NfnB}$ which reduces CB1954 at either the 4-nitro group or 2-nitro group, producing equimolar quantities of the $4 \mathrm{HX}$ derivative and much less toxic 2-hydroxylamine (2HX) derivative (5-(aziridin-1-yl)-2-hydroxylamino-4-nitrobenzamide) $[27,28]$. Moreover, the kinetic parameters of HsoNTR and NmeNTR differ dramatically from those of $E$. coli $\mathrm{NfnB}$ and other published enzymes (Table 1). Crucially, NmeNTR is the first reported enzyme with a $K_{m}{ }^{\mathrm{CB} 1954}$ lower than $6.3 \mu \mathrm{M}$, the maximum concentration of CB1954 which can be safely achieved in patient serum. NmeNTR would therefore approach saturation with CB1954 in a therapeutic regime using the maximum clinicallyrecommended dose, so the prodrug would be efficiently activated and high levels of tumor-specific cytotoxicity achieved.

\section{Construction of NTR-expressing Clostridium strains that are stable, disabled, and lack antibiotic marker genes}

To establish whether the apparently superior kinetic properties of NmeNTR would result in improved therapeutic performance, we sought to construct and compare strains of Clostridium sporogenes NCIMB 10696 expressing either NmeNTR or the most-studied CB1954activating enzyme $E$. coli $\mathrm{NfnB}$ in an in vivo model. $C$. sporogenes NCIMB 10696 is one of the tumor-targeting Clostridium strains currently most studied as a potential therapeutic agent [16-20] along with Clostridium novyi NT [29-32].

In previous CDEPT studies nitroreductases have been expressed using autonomous plasmids, but these exhibit segregational instability [33], causing the proportion of plasmid-containing cells in a population 
to decrease during growth. Therefore expression of a plasmid-borne NTR is likely to be poor and heterogenous in a tumor colonized through many generations of bacterial growth [34] following the initial infiltration of a small number of plasmid-containing spores. Plasmids also carry a risk of transfer to other organisms. To overcome these issues, we opted to use expression constructs localized to the chromosome, which has complete segregational stability and no mechanism for transfer. The insertion of heterologous expression constructs into the chromosome

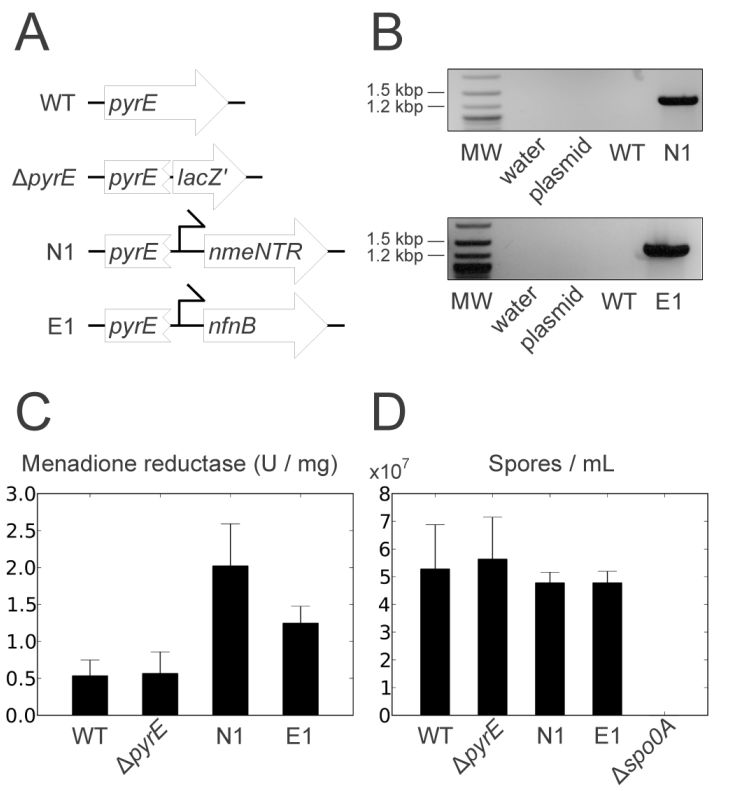

Figure 2: Construction and in vitro characterization of $C$. sporogenes therapeutic strains. $(A)$ Chromosomal pyrE locus of therapeutic strains and control strains. WT, wild type; $\triangle p y r E$, a mutant constructed previously by integrating the 'empty' cloning site (lacZ') of pMTL-JH27 [37]; N1, the strain containing a NmeNTR expression cassette; E1, the strain containing an $E$. coli $\mathrm{NfnB}$ expression cassette; angled arrows, $f d x$ promoter. $(B)$ Successful integration shown by PCR using chromosome-specific primer Csp-pyrD-sF2 in combination with insert-specific primer M13F. MW, 2-Log DNA Ladder (NEB) molecular weight marker; plasmid, pMTL-JH27 derivative containing NmeNTR or NfnB cassette accordingly; WT, wildtype C. sporogenes genomic DNA; N1 and E1, genomic DNA from strain N1 or E1 respectively. (C) Functional expression of NmeNTR and NfnB, in strains N1 and E1 respectively, indicated by specific menadione reductase activities in cell lysates. Data shown are the mean of three independent experiments, error bars show standard deviation. N1 and E1 show specific menadione reductase activities elevated above the background activity of endogenous quinone reductases seen in WT and $\Delta p y r E$. (D) NTR-expressing and control strains are equally able to form spores. Strains were grown in complex medium (TYG) for five days, heated to inactivate vegetative cells, and spore titres were determined by plating. A non-sporulating $\triangle s p o 0 A$ mutant constructed previously [35] is included as a control. Data shown are the mean of three independent experiments, error bars show standard deviation. of tumor-targeting Clostridium sp. has not previously been reported, but is now possible using methods for chromosomal integration in $C$. sporogenes that we have recently developed [35-37].

An expression cassette was constructed using a strong, constitutive promoter derived from the ferredoxin gene $f d x$ of $C$. sporogenes to direct expression of NmeNTR from a synthetic coding sequence sequence with codon usage optimized to suit $C$. sporogenes. A similar expression cassette for $E$. coli $\mathrm{NfnB}$ was also constructed. The NmeNTR expression cassette was initially inserted into the $C$. sporogenes chromosome using the ClosTron method [35, 36] which employs a modified bacterial Group II intron (a type of mobile retro-element [38]) to deliver the sequence of interest. Recombinant clones were isolated using the antibiotic erythromycin, resistance to which is conferred by the marker gene ermB within the insertion. As antibiotic resistance is undesirable in therapeutic strains, subsequent removal of erm $B$ from the chromosome using FLP recombinase was attempted, but was unsuccessful (see Supporting Information).

To circumvent the need for marker removal, we used our recently-developed integration method ACE, in which an antibiotic selection marker need not be incorporated into the chromosome along with the expression cassette [37]. NmeNTR and E. coli NfnB expression cassettes were inserted into the $C$. sporogenes chromosome using integration vector pMTL-JH27, which targets pyrE, a gene involved in pyrimidine biosynthesis. By inactivating pyrE during integration, recombinant cells are also uracil auxotrophs and effectively disabled from growth in the environment. The concept of disabling a strain to ensure containment was proposed at the advent of recombinant DNA technology [39] and has recently been applied to restrict Salmonella amino acid auxotrophs to tumors [11, 12]. Using this approach, the desired recombinant $C$. sporogenes strains containing $E$. coli $\mathrm{NfnB}$ and NmeNTR were readily obtained, and were designated E1 and N1, respectively (Figure $2 A$ and $B$ ). The 'empty' vector pMTL$\mathrm{JH} 27$ was previously used to generate a pyrE mutant without an expression cassette [37] which we used as a control in this study (Figure $2 A$ ).

\section{Strain characterization in vitro}

To determine whether the heterologous nitroreductases were functionally expressed by strains E1 and $\mathrm{N} 1$, we measured the menadione reductase activity in cell lysates of these strains and compared them to the wild type and the pyrE mutant. Cells lysates of both E1 and $\mathrm{N} 1$ contained menadione reductase activity elevated significantly above the endogenous levels measured in the controls (Figure 2C).

The disablement of E1, N1 and the pyrE mutant was confirmed by sub-culturing cells of these strains and the wild type from the complex medium TYG onto 
plates of a defined growth medium either with or without supplementary uracil. The wild type grew equally well with or without the uracil supplement, whereas E1, N1 and the pyrE mutant were unable to grow without exogenous uracil, confirming their disablement, a uracil auxotrophic phenotype.

CDEPT depends upon the ability of Clostridium to form spores, the metabolically-dormant, highly-robust form suitable for intravenous administration and for long periods of storage. Therefore it was necessary to determine whether the ability of the recombinant strains to form spores had been affected by the inactivation of $p y r E$, the addition of the NTR expression cassettes, or the subculturing steps during the genetic modification procedure. The wild type, E1, N1 and the pyrE mutant were cultivated in TYG broth, in which the wild type forms spores over time. A spo0A mutant, which is completely unable to form spores, was also included as a control [35]. Samples taken over several days were heated to inactivate vegetative cells, and the titre of heat-resistant colony-forming units (corresponding to viable spores) was determined by dilution plating (Figure 2D). The spoOA mutant formed no colonies following heat treatment, confirming that the procedure inactivated all vegetative cells. E1, N1 and the pyrE mutant were all able to form spores, and did so at the same rate as the wild type, and to the same final titer.

\section{CDEPT treatment of tumors in vivo}

Since strains E1 and N1 express stably-integrated NTR under the regulatory control of a strong promoter without inclusion of any antibiotic resistance gene, we next determined whether administration of these clinically-applicable strains in combination with prodrug administration to tumor-bearing animals would result in anti-tumor efficacy. To do so, we compared the effect in animals that received (1) no treatment, (2) CB1954 prodrug alone, (3) sham treatment (spores and vehicle), (4) pyrE mutant control spores in combination with CB1954 and (5) N1 or E1 spores in combination with CB1954, each in a standard experimental tumor growth delay setting. This choice of groups allowed us to compare the contribution of the two major improvements reported here, stable integration and improved enzyme kinetics. Spores were collected, quantified and intravenously administered at a concentration of $5 \times 10^{7} \mathrm{cfu}$ per animal when tumors reached a volume of $\sim 250 \mathrm{~mm}^{3}$, followed five days later by sham or prodrug administration. Colonization evaluation in randomly chosen tumors from each group ( $\mathrm{n} \geq 14$ per group) showed equal numbers of the C. sporogenes cells per $g$ tumor tissues for all strains, with $>99 \%$ of cfu being in the metabolically active vegetative form. Colonization was also confirmed by gram staining. In tumors, $C$. sporogenes vegetative cells are visible as purple, gram-positive rods (Figure $3 C$ ). Disablement of the strain by knocking out pyrE thus did not affect the excellent tumor-colonizing capacity of $C$. sporogenes. In line with our previous observations [19] administration of prodrug alone did not result in any effect, and only a small (non-significant) growth delay was observed upon administration of spores alone (sham) or control spores in combination with CB1954 (Figure 3 A). Strikingly, combining spores of strain E1 or N1 with CB1954
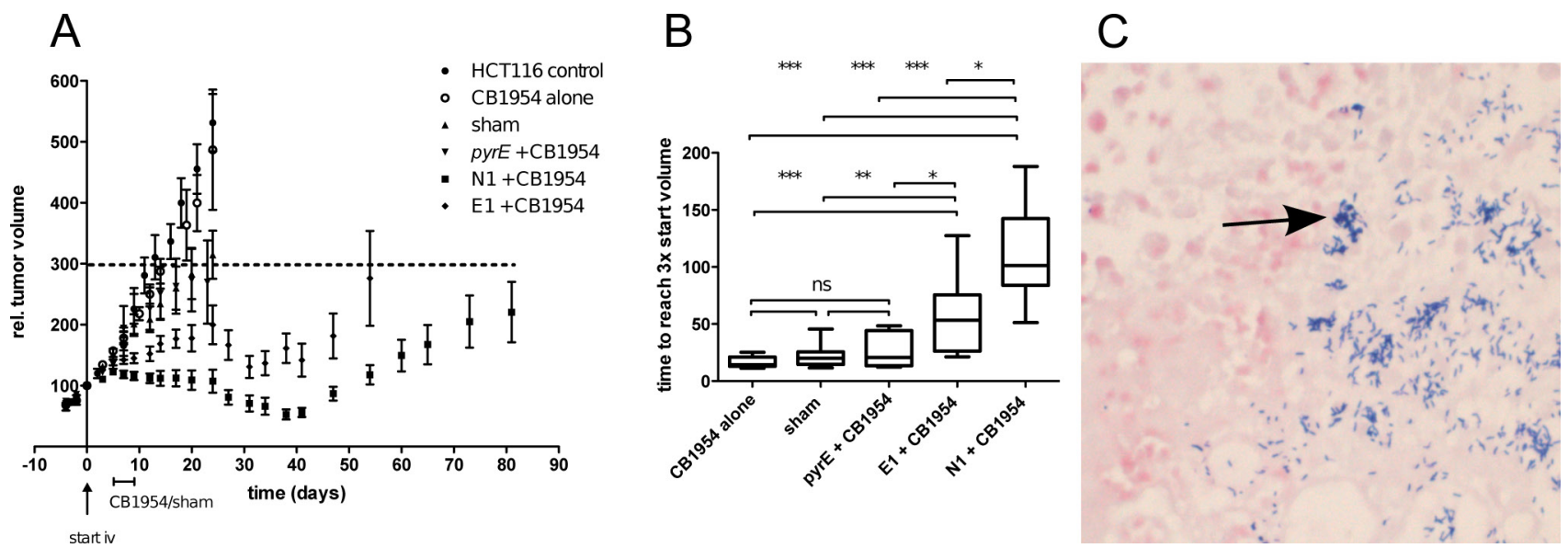

Figure 3: The NTR-expressing therapeutic strains are efficacious in CB1954 therapy in vivo. (A) Growth curves of HCT116 tumors treated as indicated in the legend. Spores $\left(5 \times 10^{7}\right)$ were injected on day 0 when tumors reached a volume of $\sim 250 \mathrm{~mm}^{3}$ and CB1954 prodrug $(15 \mathrm{mg} / \mathrm{kg})$ or sham treatment was given for 5 consecutive days starting at day 5 post spore injection. Data shown are average \pm SEM. (B) Growth delay of individual tumors in the different groups. Growth delay is defined as the time for the tumor to reach three times its volume at the start of the prodrug or sham treatment. Statistical differences between groups are calculated using the non-parametric Mann-Whitney test $(*, \mathrm{p}<0.05 ; * *, \mathrm{p}<0.01 ; *, p<0.001)$ (C) Representative gram staining of tumor sections showing colonization of the tumor by $C$. sporogenes vegetative cells following spore administration, germination in the tumor, and outgrowth. C. sporogenes vegetative cells are visible as gram-positive purple rods and reside in the necrotic area of the tumor. HCT116 nuclei (pink) are counterstained with iodine solution. 
resulted in a significant growth delay, the effect being most pronounced for $\mathrm{N} 1(\mathrm{p}<0.001$, Figure $3 B)$. This suggests that the superior kinetic properties of NmeNTR, which allow conversion of the prodrug to its toxic derivative at a much lower concentration than $E$. coli $\mathrm{NfnB}$, contribute substantially to the observed effect. The most striking effect we observed was the disappearance of several tumors in both CDEPT groups. In the E1/CB1954 group, two out of 16 tumors completely disappeared and in the N1/CB1954 four out of 16 tumors completely disappeared (Figure S1). During the treatment, a mild and transient weight loss could be observed and the animals recovered completely during further follow-up time.

\section{DISCUSSION}

The poor activity of known nitroreductases at clinically-relevant CB1954 concentrations has led to several previous attempts to obtain an enzyme with more suitable kinetic properties, by screening native enzymes [26, 40-43] and/or protein engineering [43-47] with some success. However, NmeNTR, the $N$. meningitidis homolog of $E$. coli nitroreductase $\mathrm{NfnB}$ reported here, is the first example of an enzyme with a $K_{m}{ }^{\mathrm{CB} 1954}$ value that can be exceeded by the clinically-achievable serum concentration of the prodrug. This $K_{m}{ }^{\mathrm{CB} 1954}$ value $(2.47 \mu \mathrm{M})$ is also sevenfold lower than the lowest previously reported (NfsA, 18 $\mu \mathrm{M}$, Table 1). This key improvement makes NmeNTR much more suitable for clinical application than other known enzymes.

NmeNTR reduces only the 4-nitro group of CB1954, producing the highly-cytotoxic 4HX derivative, unlike $E$. coli $\mathrm{NfnB}$ which produces both the $4 \mathrm{HX}$ and $2 \mathrm{HX}$ derivatives in similar proportions [27, 28]. Among the enzymes whose CB1954 nitroreductase activity has now been characterized, specificity for the 4-nitro group appears to be typical (Table 1). E. coli NfnB, although the most widely studied CB1954 nitroreductase, is unusual in this respect. The $4 \mathrm{HX}$ derivative is far more cytotoxic than the 2HX derivative [22] which suggests that an enzyme such as NmeNTR with specificity for the 4-nitro group would lead to greater tumor-specific cytotoxicity.

By localizing expression cassettes to the chromosome using double crossover homologous recombination, we have constructed stable strains that lack both antibiotic resistance markers and any mechanism for transfer of the heterologous sequence. This feature represents a major improvement over previous studies in terms of efficacy and safety, as the instability of known plasmid replicons in $C$. sporogenes has been established [33] and transfer of natural and recombinant conjugal plasmids and transposons is known to occur in C. sporogenes and close relatives.

$C$. sporogenes is naturally confined to the hypoxic tumor core by oxygen, and the disabling pyrE mutation we introduce would serve to severely limit growth of modified strains in the environment in the event of accidental release from a clinical setting. Tumor containment and/ or targeting features have been described for other recombinant bacterial strains with anti-tumor potential, such as Salmonella $[11,12]$. The use of elegant synthetic regulatory mechanisms has also been proposed for containment [4] but we are cautious of their use for this purpose, and suggest that physiological mechanisms may be more appropriate. Any system in which containment depends upon the continued function of introduced component(s) will be vulnerable to failure through spontaneous loss-of-function mutations. Such mutations are inevitable at some frequency, and mutants would have a selective advantage for growth outside the tumor, so these systems would be inherently fragile. In contrast, no loss-of-function mutation is likely to allow an auxotrophic mutant of a strict anaerobe, as reported here, to escape the tumor environment.

Our approach to constructing stable, disabled, antibiotic marker-free strains of Clostridium expressing heterologous genes represents a platform for future efforts to build upon, as it provides a tumor-specific delivery system for the development of safe and effective gene therapies. The novel PCE NmeNTR in combination with CB1954 is a promising candidate. Besides cytotoxicity, strains could be engineered to have additional clinicallyuseful properties. For example, we are currently working to enable imaging of tumors undergoing Clostridium therapy via clinically-relevant imaging modalities such as PET. With the key strain engineering challenges overcome, a clinical trial to realize this therapy is now in prospect.

\section{METHODS}

Full methods are given in SI Appendix, Methods.

\section{Enzyme characterization}

Genes encoding homologs of $n f n B$ and $y w r O$ were PCR-amplified from genomic DNA or cell lysates. $E$. coli expression plasmids for each gene were constructed by standard methods. Menadione reductase activities of lysates of $E$. coli cells containing the expression plasmids were determined using a spectrophotometric assay, and CB1954 nitroreductase activities of lysates were determined using an HPLC assay. Specific activities were calculated using protein concentrations of lysates determined using the Bradford assay. The 4HX and $2 \mathrm{HX}$ derivatives of CB1954 were identified with reference to standards, their known absorbance spectra, and their anticipated column retention times. For determination of kinetic parameters using the same CB1954 nitroreductase assay, NTR expression plasmids were modified to encode C-terminal 6xHis tags, and enzymes were purified using a Novagen His-Bind kit. 


\section{Construction of recombinant $C$. sporogenes}

C. sporogenes was cultured anaerobically. Plasmids were transferred to $C$. sporogenes by conjugation from an E. coli donor as described previously [33]. Expression cassettes for NmeNTR and E. coli NfnB were constructed using derivatives of the $f d x$ promoter from $C$. sporogenes and a synthetic, codon-optimized gene (Entelechon $\mathrm{GmbH})$. Expression cassettes were initially inserted into the $C$. sporogenes chromosome using the $p y r F-$ specific Group II intron plasmid pMTL007C-E2::CsppyrF-595s, and FLP-mediated removal of the ermB attempted as described previously [36]. Subsequently, expression cassettes were inserted into the $C$. sporogenes chromosome using the $p y r E$ integration plasmid pMTL$\mathrm{JH} 27$ as described previously [37].

\section{Characterization of recombinant $C$. sporogenes}

Menadione reductase activities of lysates of $C$. sporogenes cells were determined to establish functional expression of the heterologous NTRs. Uracil auxotrophy / prototrophy was determined by sub-culturing fresh $C$. sporogenes colonies grown on the complex medium TYG onto plates of the defined growth medium MI either with or without supplementary uracil. Spores titres were determined as colony-forming units resistant to heattreatment at $80^{\circ} \mathrm{C}$ for 20 minutes.

\section{Mouse xenograft tumor model}

Human colorectal HCT116 carcinoma cells were injected subcutaneously into adult NMRI nu/nu mice. Tumor volumes were determined three times per week using calipers. $5 \times 10^{7}$ spores were administered when tumors reached a volume of $\sim 250 \mathrm{~mm}^{3}$, and sham or prodrug treatment was started five days later. CB1954 was administered intraperitoneally at a concentration of $15 \mathrm{mg} / \mathrm{kg}$ for five consecutive days. At the end of the follow-up period, colonization levels were determined in tumors and normal tissues as described previously [48]. Tumor growth delay was determined as the time from the start of the treatment necessary for a tumor to triple in volume. Statistical significance was tested using a nonparametric Mann Whitney test. All animal testing was performed in accordance with local institutional guidelines and approved by the Animal Ethics Committee.

\section{ACKNOWLEDGEMENTS}

This work was supported by Biotechnology and Biological Sciences Research Council (BBSRC) grant BB/ G016224/1, ZonMw grant ID 4340 0009, The University of Nottingham, the University Hospital of Maastricht and
Morvus Technology Ltd.

\section{REFERENCES}

1. NIH. Assessment of adenoviral vector safety and toxicity: report of the National Institutes of Health Recombinant DNA Advisory Committee. Hum Gene Ther. 2012; 13:313.

2. Hacein-Bey-Abina S, Garrigue A, Wang GP, Soulier J, Lim A, Morillon E, Clappier E, Caccavelli L, Delabesse E, Beldjord K, Asnafi V, MacIntyre E, Dal Cortivo L, Radford I et al. Insertional oncogenesis in 4 patients after retrovirusmediated gene therapy of SCID-X1. J Clin Invest. 2008; 118:3132-3142.

3. Breitbach CJ, Burke J, Jonker D, Stephenson J, Haas AR, Chow LQ, Nieva J, Hwang TH, Moon A, Patt R, Pelusio A, Le Boeuf F, Burns J et al. Intravenous delivery of a multimechanistic cancer-targeted oncolytic poxvirus in humans. Nature. 2011; 477:99-102.

4. Forbes NS. Engineering the perfect (bacterial) cancer therapy. Nat Rev Cancer. 2010; 10:785-794.

5. Mengesha A, Dubois L, Chiu RK, Paesmans K, Wouters BG, Lambin P and Theys J. Potential and limitations of bacterial-mediated cancer therapy. Front Biosci. 2007; 12:3880-3891.

6. Malmgren RA and Flanigan CC. Localization of the vegetative form of Clostridium tetani in mouse tumors following intravenous spore administration. Cancer Res. $1955 ; 15: 473-478$.

7. Moese JR and Moese G. Oncolysis by clostridia. I. Activity of Clostridium butyricum (M-55) and other nonpathogenic clostridia against the Ehrlich carcinoma. Cancer Res. 1964; 24:212-216.

8. Carey RW, Holland JF, Whang HY, Neter E and Bryant B. Clostridial oncolysis in man. Eur J Cancer. 1967; 3:37-46.

9. Pipiya T, Sauthoff H, Huang YQ, Chang B, Cheng J, Heitner S, Chen S, Rom WN and Hay JG. Hypoxia reduces adenoviral replication in cancer cells by downregulation of viral protein expression. Gene Ther. 2005; 12:911-917.

10. Shen BH and Hermiston TW. Effect of hypoxia on Ad5 infection, transgene expression and replication. Gene Ther. 2005; 12:902-910.

11. Zhao M, Yang M, Li XM, Jiang P, Baranov E, Li S, Xu M, Penman S and Hoffman RM. Tumor-targeting bacterial therapy with amino acid auxotrophs of GFP-expressing Salmonella typhimurium. Proc Natl Acad Sci U S A. 2005; 102:755-760.

12. Zhao M, Geller J, Ma H, Yang M, Penman S and Hoffman RM. Monotherapy with a tumor-targeting mutant of Salmonella typhimurium cures orthotopic metastatic mouse models of human prostate cancer. Proc Natl Acad Sci U S A. 2007; 104:10170-10174.

13. Minton NP, Brown JM, Lambin P and Anné J. Clostridia - Biotechnology and Medical Applications. eds Bahl H, 
Dürre P (Wiley-VCH Verlag GmbH) 2005.

14. Minton NP. Clostridia in cancer therapy. Nat Rev Microbiol. 2003; 1:237-242.

15. Minton NP, Mauchline ML, Lemmon MJ, Brehm JK, Fox M, Michael NP, Giaccia A and Brown JM. Chemotherapeutic tumour targeting using clostridial spores. FEMS Microbiol Rev. 1995; 17:357-364.

16. Lemmon MJ, van Zijl P, Fox ME, Mauchline ML, Giaccia AJ, Minton NP and Brown JM. Anaerobic bacteria as a gene delivery system that is controlled by the tumor microenvironment. Gene Ther. 1997; 4:791-796.

17. Fox ME, Lemmon MJ, Giaccia AJ, Minton NP and Brown JM. Genetically modified Clostridium for gene therapy of tumors. Methods Mol Med. 2000; 35:413-418.

18. Liu SC, Minton NP, Giaccia AJ and Brown JM. Anticancer efficacy of systemically delivered anaerobic bacteria as gene therapy vectors targeting tumor hypoxia/necrosis. Gene Ther. 2002; 9:291-296.

19. Theys J, Pennington O, Dubois L, Anlezark G, Vaughan T, Mengesha A, Landuyt W, Anné J, Burke PJ, Dûrre P, Wouters BG, Minton NP and Lambin P. Repeated cycles of Clostridium-directed enzyme prodrug therapy result in sustained antitumour effects in vivo. Br J Cancer. 2006; 95:1212-1219.

20. Liu SC, Ahn GO, Kioi M, Dorie MJ, Patterson AV and Brown JM. Optimized Clostridium-directed enzyme prodrug therapy improves the antitumor activity of the novel DNA cross-linking agent PR-104. Cancer Res. 2008 68:7995-8003.

21. Chung-Faye G, Palmer D, Anderson D, Clark J, Downes M, Baddeley J, Hussain S, Murray PI, Searle P, Seymour L, Harris PA, Ferry D and Kerr DJ. Virus-directed, enzyme prodrug therapy with nitroimidazole reductase: a phase I and pharmacokinetic study of its prodrug, CB1954. Clin Cancer Res. 2001 7:2662-2668.

22. Knox RJ, Friedlos F, Jarman M and Roberts JJ. A new cytotoxic, DNA interstrand crosslinking agent, 5-(aziridin1-yl)-4-hydroxylamino-2-nitrobenzamide, is formed from 5-(aziridin-1-yl)-2,4-dinitrobenzamide (CB 1954) by a nitroreductase enzyme in Walker carcinoma cells. Biochem Pharmacol. 1988; 37:4661-4669.

23. Palmer DH, Milner AE, Kerr DJ and Young LS. Mechanism of cell death induced by the novel enzyme-prodrug combination, nitroreductase/CB1954, and identification of synergism with 5-fluorouracil. Br J Cancer. 2003; 89:944 950 .

24. Cui W, Gusterson B and Clark AJ. Nitroreductasemediated cell ablation is very rapid and mediated by a p53-independent apoptotic pathway. Gene Ther. 1999; 6: 764-770.

25. Michael NP, Brehm JK, Anlezark GM and Minton NP. Physical characterisation of the Escherichia coli B gene encoding nitroreductase and its over-expression in Escherichia coli K12. FEMS Microbiol Lett. 1994;
124:195-202.

26. Anlezark GM, Vaughan T, Fashola-Stone E, Michael NP, Murdoch H, Sims MA, Stubbs S, Wigley S and Minton NP. Bacillus amyloliquefaciens orthologue of Bacillus subtilis ywrO encodes a nitroreductase enzyme which activates the prodrug CB 1954. Microbiology. 2002; 148:297-306.

27. Anlezark GM, Melton RG, Sherwood RF, Coles B, Friedlos F and Knox RJ. The bioactivation of 5-(aziridin-1-yl)-2,4dinitrobenzamide (CB1954)-I. Purification and properties of a nitroreductase enzyme from Escherichia coli-a potential enzyme for antibody-directed enzyme prodrug therapy (ADEPT). Biochem Pharmacol. 1992; 44:22892295.

28. Knox RJ, Friedlos F, Sherwood RF, Melton RG and Anlezark GM. The bioactivation of 5-(aziridin-1-yl)2,4-dinitrobenzamide (CB1954)-II. A comparison of an Escherichia coli nitroreductase and Walker DT diaphorase. Biochem Pharmacol. 1992; 44:2297-2301.

29. Bettegowda C, Huang X, Lin J, Cheong I, Kohli M, Szabo SA, Zhang X, Diaz LA Jr, Velculescu VE, Parmigiani G, Kinzler KW, Vogelstein B and Zhou S. The genome and transcriptomes of the anti-tumor agent Clostridium novyiNT. Nat Biotechnol. 2006; 24: 1573-1580.

30. Diaz LA Jr, Cheong I, Foss CA, Zhang X, Peters BA, Agrawal N, Bettegowda C, Karim B, Liu G, Khan K, Huang X, Kohli M, Dang LH et al. Pharmacologic and toxicologic evaluation of C. novyi-NT spores. Toxicol Sci. 2005; 88:562-575.

31. Smith AB 3rd, Freeze BS, LaMarche MJ, Sager J, Kinzler KW and Vogelstein B. Discodermolide analogues as the chemical component of combination bacteriolytic therapy. Bioorg Med Chem Lett. 2005; 15:3623-3626.

32. Dang LH, Bettegowda C, Huso DL, Kinzler KW and Vogelstein B. Combination bacteriolytic therapy for the treatment of experimental tumors. Proc Natl Acad Sci U S A. 2001; 98:15155-15160.

33. Heap JT, Pennington OJ, Cartman ST and Minton NP. A modular system for Clostridium shuttle plasmids. J Microbiol Methods. 2009;78: 79-85.

34. Danino T, Lo J, Prindle A, Hasty J and Bhatia SN. In Vivo Gene Expression Dynamics of Tumor-Targeted Bacteria. ACS Synthetic Biology. 2012; 1:465-470.

35. Heap JT, Pennington OJ, Cartman ST, Carter GP and Minton NP. The ClosTron: a universal gene knock-out system for the genus Clostridium. J Microbiol Methods. 2007; 70:452-464.

36. Heap JT, Kuehne SA, Ehsaan M, Cartman ST, Cooksley CM, Scott JC and Minton NP. The ClosTron: Mutagenesis in Clostridium refined and streamlined. J Microbiol Methods. 2010; 80:49-55.

37. Heap JT, Ehsaan M, Cooksley CM, Ng YK, Cartman $\mathrm{ST}$, Winzer K and Minton NP. Integration of DNA into bacterial chromosomes from plasmids without a counterselection marker. Nucleic Acids Res. 2012; 40:59. 
38. Lambowitz AM and Zimmerly S. Mobile group II introns. Annu Rev Genet. 2004; 38:1-35.

39. Berg P, Baltimore D, Brenner S, Roblin RO and Singer MF. Summary statement of the Asilomar conference on recombinant DNA molecules. Proc Natl Acad Sci U S A. 1975; 72:1981-1984.

40. Emptage CD, Knox RJ, Danson MJ and Hough DW. Nitroreductase from Bacillus licheniformis: a stable enzyme for prodrug activation. Biochem Pharmacol. 2009; 77:2129.

41. Vass SO, Jarrom D, Wilson WR, Hyde EI and Searle PF. E. coli NfsA: an alternative nitroreductase for prodrug activation gene therapy in combination with CB1954. Br J Cancer. 2009; 100:1903-1911.

42. Prosser GA, Copp JN, Syddall SP, Williams EM, Smaill JB, Wilson WR, Patterson AV and Ackerley DF. Discovery and evaluation of Escherichia coli nitroreductases that activate the anti-cancer prodrug CB1954. Biochem Pharmacol. 2010; 79:678-687.

43. Swe PM, Copp JN, Green LK, Guise CP, Mowday AM, Smaill JB, Patterson AV and Ackerley DF. Targeted mutagenesis of the Vibrio fischeri flavin reductase FRase I to improve activation of the anticancer prodrug CB1954. Biochem Pharmacol. 2012; 84:775-783.

44. Grove JI, Lovering AL, Guise C, Race PR, Wrighton CJ, White SA, Hyde EI and Searle PF. Generation of Escherichia coli nitroreductase mutants conferring improved cell sensitization to the prodrug CB1954. Cancer Res. 2003; 63: 5532-5537.

45. Race PR, Lovering AL, White SA, Grove JI, Searle PF, Wrighton CW and Hyde EI. Kinetic and structural characterisation of Escherichia coli nitroreductase mutants showing improved efficacy for the prodrug substrate CB1954. J Mol Biol. 2007; 368: 481-492.

46. Jarrom D, Jaberipour M, Guise CP, Daff S, White SA, Searle PF and Hyde EI. Steady-state and stopped-flow kinetic studies of three Escherichia coli NfsB mutants with enhanced activity for the prodrug CB1954. Biochemistry. 2009; 48:7665-7672.

47. Jaberipour M, Vass SO, Guise CP, Grove JI, Knox RJ, Hu L, Hyde EI and Searle PF. Testing double mutants of the enzyme nitroreductase for enhanced cell sensitisation to prodrugs: effects of combining beneficial single mutations. Biochem Pharmacol. 2010; 79:102-111.

48. Lambin P, Theys J, Landuyt W, Rijken P, van der Kogel A, van der Schueren E, Hodgkiss R, Fowler J, Nuyts S, de Bruijn E, Van Mellaert L and Anné J. Colonisation of Clostridium in the body is restricted to hypoxic and necrotic areas of tumours. Anaerobe. 1998; 4:183-188. 